\title{
Double blind cross-over placebo controlled study of omeprazole in the treatment of patients with reflux symptoms and physiological levels of acid reflux - the "sensitive oesophagus"
}

\author{
R G P Watson, T C K Tham, B T Johnston, N I McDougall
}

\begin{abstract}
Background-At least $10-15 \%$ of patients with reflux symptoms have a normal endoscopy and physiological levels of acid reflux on pH monitoring. Such patients with $50 \%$ or more of symptoms associated with acid reflux episodes have "a positive symptom index" (SI), and it has been proposed that this defines the "sensitive oesophagus".

Aim-To test the response to omeprazole $20 \mathrm{mg}$ twice daily for four weeks of patients with normal levels of acid reflux using a randomised, placebo controlled, double blind, cross-over design.

Patients-Eighteen patients with normal levels of reflux, 12 of whom had a positive SI.

Methods-Response was measured by symptomatic assessment and the SF-36 quality of life (QOL) questionnaire.

Results-Patients with a positive SI showed the following improvements on omeprazole compared with placebo: decrease in symptom frequency $(p<0.01)$, severity $(p<0 \cdot 01)$ and consumption of antacids $(p<0.01)$. In the group with a negative SI only one patient clearly improved. The QOL parameters for bodily pain (65.6 $v 53.4, p=0.03)$ and vitality $(60.6 v 48 \cdot 8$, $p=0 \cdot 049$ ) were significantly better on omeprazole than placebo for the group overall.

Conclusion-Omeprazole improves symptoms in 11 of 18 patients with normal endoscopy and pH monitoring, particularly those with a positive SI. This supports the theory that such patients have an oesophagus which is "sensitive" to acid reflux and are part of the GORD spectrum.

(Gut 1997; 40: 587-590)
\end{abstract}

Keywords: GORD, physiological reflux, oesophageal sensitivity, omeprazole, symptom index.

Department of Medicine, The Queen's University, Belfast R G P Watson T C K Tham B T Johnston N I McDougal

Correspondence to: Dr R G P Watson, Department of Medicine, Institute of Clinical Science, The Queen's University Belfast, Grosvenor Road, Belfast BT12 6BJ.

Accepted for publication 15 October 1996

Gastro-oesophageal reflux disease (GORD) is defined as oesophageal inflammatory change or symptoms, or both, caused by gastrooesophageal reflux. Oesophagitis is found in $50-68 \%$ of patients with symptoms of GORD who present to a doctor but the remainder have no macroscopic endoscopic changes. ${ }^{1-4}$ Where there are no inflammatory changes, ambulatory $\mathrm{pH}$ monitoring has proved to be particularly useful in establishing a diagnosis of GORD and directing management. ${ }^{5}$ By convention, GORD is diagnosed by ambulatory $\mathrm{pH}$ monitoring when the total duration of distal oesophageal exposure to acid $(\mathrm{pH}<4)$ is in excess of the normal range. In our laboratory this is taken as the 95th percentile of a normal control group of adult subjects ( $\mathrm{pH}<4$ for $\geq 5 \%$ of total recording time). ${ }^{6}$

A small proportion (10-15\%) of patients with GORD have both normal endoscopy and a total acid exposure within normal limits. ${ }^{7}$ In such cases, a further useful assessment is the symptom index (SI) which may be calculated from the $\mathrm{pH}$ study based on the number of symptom events during a recording which correlate with episodes of acid reflux $(\mathrm{pH}<4) .{ }^{89}$ It is suggested that an SI of $50 \%$ or greater is indicative of GORD, even in the context of a total acid exposure within normal limits. Such patients seem to have an enhanced perception of normal reflux events, ${ }^{10}{ }^{11}$ a condition which might be best described as a "sensitive oesophagus".

Traditional measures of morbidity and mortality are now thought to be inadequate determinants of patient outcomes, ${ }^{12}{ }^{13}$ and in recent years a number of tools for measuring quality of life (QOL) have been developed. The Short Form-36 (SF-36) is widely regarded as one of the most useful generic tools for assessing patient quality of life. Initial studies in the United Kingdom have shown that the SF-36 is reliable, reproducible and sensitive. ${ }^{12-14}$ It has also recently been used to demonstrate that treatment of oesophagitis improves several quality of life parameters. ${ }^{15}$ As yet, there are no published data using the SF-36 in patients with a "sensitive oesophagus".

If the "sensitive oesophagus" is a real entity, it is predicted that patients should respond to conventional treatment for GORD. Therefore, the aim of this study was to test the response to omeprazole versus placebo in a randomised, double blind, cross-over trial using both symptomatic assessment and the SF-36 to assess changes in quality of life.

\section{Methods}

For a 12 month period from October 1993 consecutive patients were recruited from our regional ambulatory $\mathrm{pH}$ monitoring service if they fulfilled the following entry criteria: normal gastroscopy, heartburn or acid regurgitation, 
or both, confirmed by daily diary card, and ambulatory $\mathrm{pH}$ monitoring showing $\mathrm{pH}<4$ for less than $5 \%$ of the total observation time and at least one symptom episode during monitoring. During $\mathrm{pH}$ monitoring, patients pressed an event button and recorded in a diary card each time they experienced their typical reflux symptoms. A symptom was regarded as reflux related if it occurred coincidentally with or within two minutes of a reflux episode $(\mathrm{pH}<4)$. The SI was calculated as (number of reflux related symptoms/all symptoms) $\times 100$. Patients were required not to take any antacid treatment other than alginate tablets for one week prior to $\mathrm{pH}$ monitoring and during monitoring. The study was approved by the university medical ethics committee and patients entering the study gave their fully informed consent.

The design of the study was a randomised, double blind, cross-over trial of omeprazole versus placebo in all subjects. The dose of omeprazole was $20 \mathrm{mg}$ twice daily and each treatment was given for four weeks. At the start of the trial, and at four and eight weeks, patients completed the SF-36 quality of life questionnaire (which gives a score ranging from zero to 100 for each of eight quality of life parameters) and patient symptoms were scored

Quality of life (QOL) scores before and after treatment. $A$ higher score represents better quality of life

\begin{tabular}{lllll}
\hline & $\begin{array}{l}\text { Baseline QOL } \\
\text { score (SEM) }\end{array}$ & $\begin{array}{l}\text { QOL after } \\
\text { omeprazole (SEM) }\end{array}$ & $\begin{array}{l}\text { QOL after } \\
\text { placebo (SEM) }\end{array}$ & $\begin{array}{l}\text { p Value for differences } \\
\text { between treatments }\end{array}$ \\
\hline Physical function & $72 \cdot 9(4 \cdot 9)$ & $77 \cdot 6(4 \cdot 9)$ & $74 \cdot 4(4 \cdot 8)$ & $0 \cdot 3$ \\
Role - physical & $38 \cdot 2(10 \cdot 1)$ & $66 \cdot 2(10 \cdot 5)$ & $48 \cdot 5(11 \cdot 8)$ & $0 \cdot 1$ \\
Bodily pain & $42 \cdot 0(5 \cdot 3)$ & $65 \cdot 6(5 \cdot 9)$ & $53 \cdot 4(4 \cdot 7)$ & $0 \cdot 03^{\star}$ \\
General health & $51 \cdot 9(4 \cdot 6)$ & $59 \cdot 0(4 \cdot 3)$ & $54 \cdot 2(4 \cdot 0)$ & $0 \cdot 3$ \\
Vitality & $52 \cdot 4(5 \cdot 2)$ & $60 \cdot 6(5 \cdot 4)$ & $48 \cdot 8(5 \cdot 2)$ & $0 \cdot 049^{\star}$ \\
Role - emotional & $50 \cdot 9(10 \cdot 7)$ & $68 \cdot 6(10 \cdot 1)$ & $58 \cdot 8(10 \cdot 9)$ & $0 \cdot 4$ \\
Social function & $41 \cdot 2(3 \cdot 8)$ & $61 \cdot 8(5 \cdot 6)$ & $56 \cdot 5(5 \cdot 6)$ & $0 \cdot 3$ \\
Mental health & $62 \cdot 8(4 \cdot 8)$ & $70 \cdot 8(4 \cdot 1)$ & $66 \cdot 6(4 \cdot 8)$ & $0 \cdot 3$ \\
\hline
\end{tabular}

*Statistically significant.
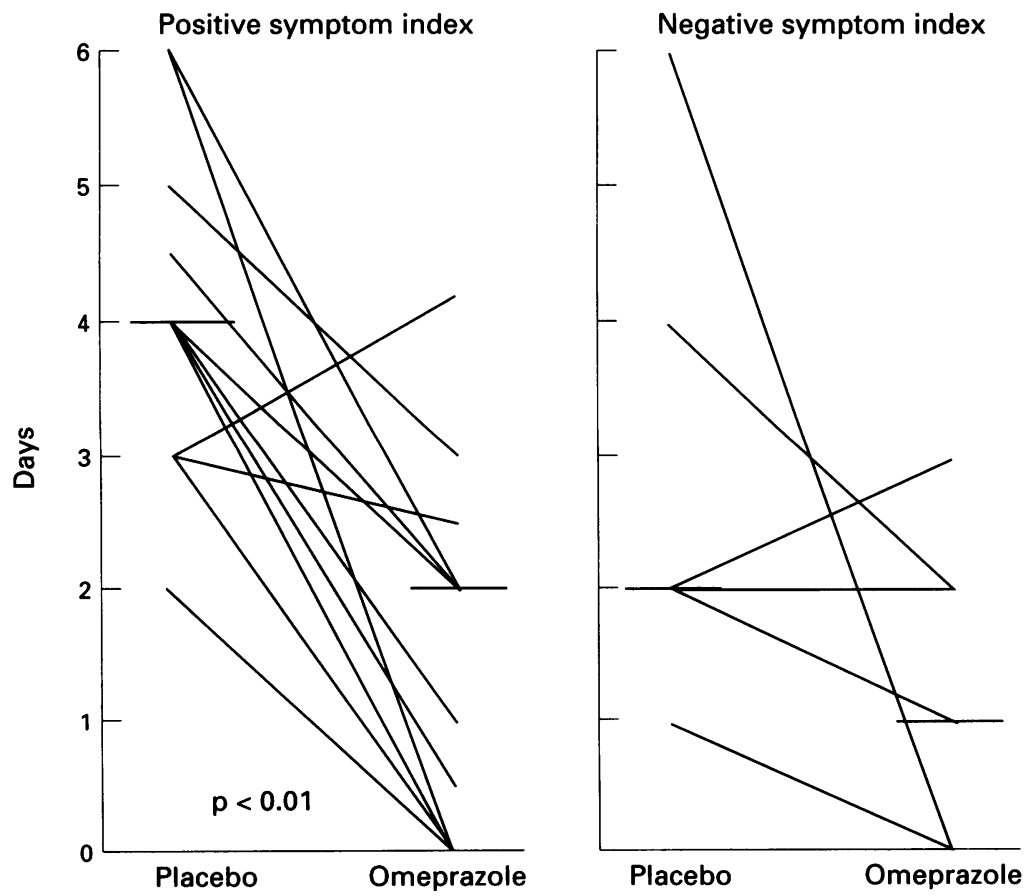

Figure 1: Reflux symptom scores (heartburn and regurgitation). by an investigator-administered questionnaire. "Reflux" symptoms, comprising heartburn and acid regurgitation, were each scored as absent, mild, moderate, or severe, corresponding to scores of $0,1,2$, and 3 , respectively. The definition of mild was where the patient required prompting to recall that a symptom was present; moderate where the patient was aware of a symptom but it did not interfere with daily activity; and severe where the patient was very aware of a symptom which interfered with daily activity. The maximum possible score for severe symptoms was 6 . Other upper gastrointestinal symptoms were scored in the same way. These comprised epigastric discomfort, post-prandial fullness, early satiety, anorexia, nausea, belching, vomiting, pain on swallowing, nocturnal cough, and nocturnal wheeze. We have designated this group of symptoms "associated symptoms" and the maximum possible score for severe symptoms was 30 .

At four and eight weeks, at the end of each treatment period, patients were asked to say whether they were the "same", "better" or "worse" compared with the previous four weeks. For statistical comparison, these symptom states were scored $0,+1$ and -1 , respectively.

Patients were asked to maintain a simple diary card on which they recorded each day whether or not they had their typical symptoms during the day or during the night, or both. They also recorded whether or not they took any alginate tablets. The average number of days per week with symptoms, and the average number of days per week when they used additional alginate tablets were determined from these diaries for each patient during the two treatment periods.

Statistical comparisons between scores on omeprazole and placebo were by paired sign test, except for QOL scores which were by $t$ test for paired samples.

\section{Results}

Over 12 months, 244 patients were referred for ambulatory $\mathrm{pH}$ monitoring, $44(18 \%)$ of whom fulfilled the entry criteria. Fifteen were not invited to take part because they lived outside the greater Belfast area. Nineteen $(65 \%)$ of the remaining 29 were recruited, 13 with a positive SI $(\geq 50 \%)$ and six with a negative SI $(<50 \%)$. There were six men, 13 women, age range 22-79 years, mean $41 \cdot 7$. Sixteen completed the trial; two dropped out in their second treatment period because of recurrence of severe symptoms and one because of unacceptable side effects. The two patients with recurrence of severe symptoms were regarded as treatment failures and were included in the final analysis. Twelve patients had a positive SI and six a negative SI.

Twelve $(67 \%)$ of the 18 patients reported a better overall level of symptoms with omeprazole compared with placebo $(p<0 \cdot 01)$. Five patients reported no difference between the two treatments and one patient was worse on omeprazole compared with placebo. This was also reflected by the quality of life assessment 
(Table). The SF-36 was completed on all three visits by 17 patients- 11 from the positive SI subgroup and six from the negative SI group. The Table shows the baseline QOL results for the eight parameters in the overall group along with the results at the end of omeprazole treatment and at the end of placebo treatment. The scores for the parameters of bodily pain and vitality were both significantly better with omeprazole compared with placebo.

When patients were divided into those with a positive or negative SI, $10(83 \%)$ of 12 patients in the positive SI subgroup reported a better level of overall symptoms with omeprazole compared with placebo $(p<0.02)$. In the
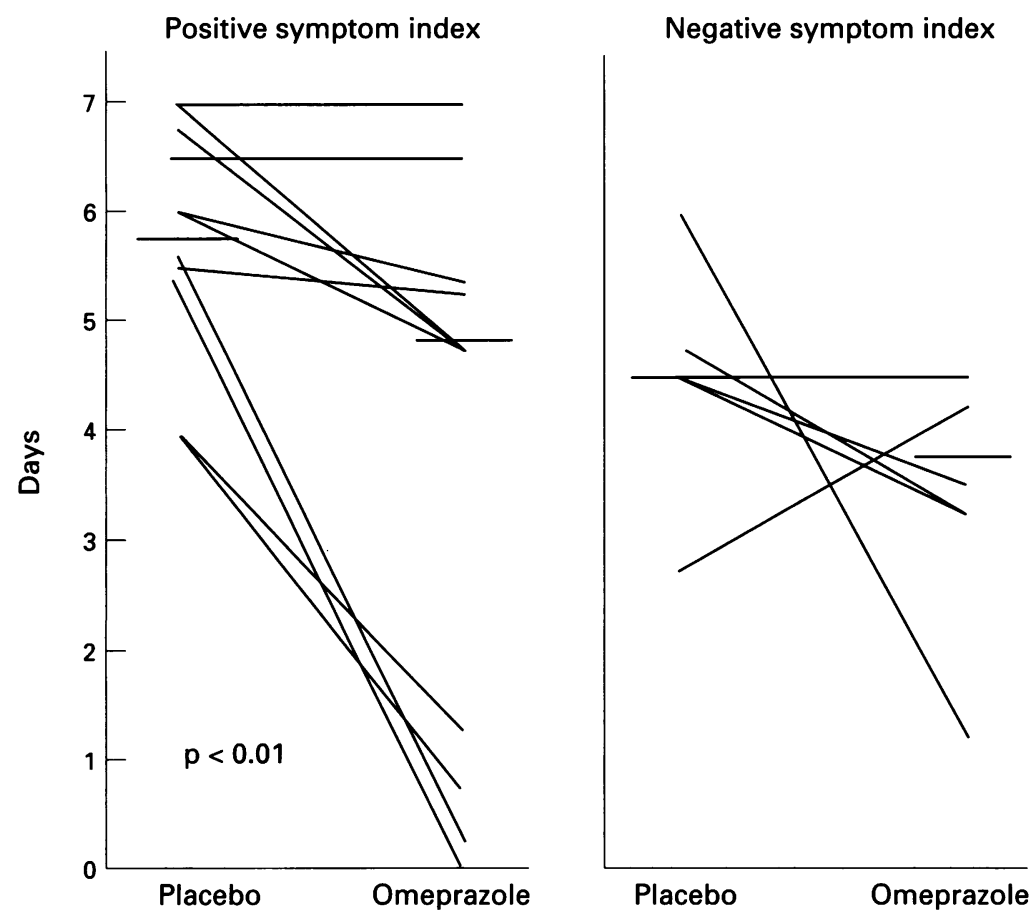

Figure 2: Days per week of reflux symptoms.

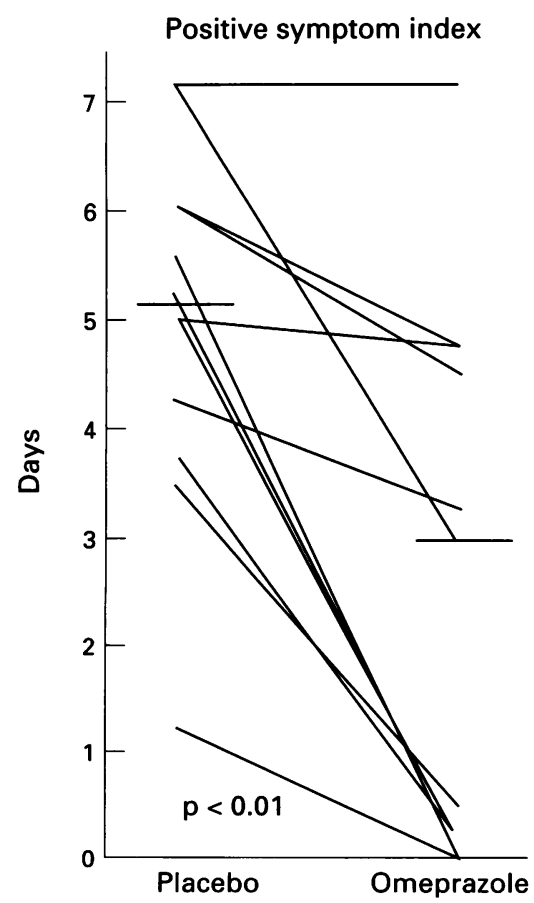

Figure 3: Days per week when alginate used. negative SI subgroup there was no significant difference, although one patient reported a dramatic improvement with omeprazole. In the positive SI subgroup there was a significant decrease in heartburn and acid regurgitation scores (median 2.0 $v 4.0 \quad(\mathrm{p}<0.01)$ (Fig 1), average number of days per week with symptoms (median $4.75 v 5.8(\mathrm{p}<0.01)$ (Fig 2), and average number of days per week when additional alginate tablets were used (median $3.0 v 5.1(\mathrm{p}<0.01)$ (Fig 3). In the negative SI subgroup there were no significant differences for the same comparisons of treatment effects (Figs 1-3). Scores for "associated symptoms" were not different on the two treatments for the overall group (median $5.5 v 4.25(\mathrm{p}=0.8)$ or within either the positive SI or negative SI subgroups.

For QOL assessment there were no differences in baseline scores before treatment for the positive SI and negative SI subgroups. Treatment with omeprazole in the positive SI subgroup resulted in a significant improvement in several QOL parameters from baseline: vitality $(p=0.007)$, social function $(p=0.03)$, role physical $(p=0.046)$, role emotional $(p=0.04)$, and bodily pain $(p=0.006)$. However, there was no significant difference in these scores compared with placebo. In the negative SI subgroup there was no improvement from baseline QOL with omeprazole and no difference from placebo.

\section{Discussion}

This study shows that some patients with reflux symptoms, normal endoscopy and physiological levels of reflux do respond well to acid suppression therapy. The majority $(67 \%)$ showed an improvement in symptoms and the group as a whole showed a significant improvement in both the bodily pain and vitality parameters of quality of life. The benefits of acid suppression treatment were much more notable in those with a positive SI. However, there were exceptions, with two positive SI patients not responding as expected, and at least one patient in the negative SI subgroup who clearly benefited from omeprazole. There is, therefore, the danger, even after extension of the definition of GORD to include cases of "sensitive oesophagus" as defined by $\mathrm{pH}$ monitoring, that some patients will be excluded who could have been successfully treated by acid suppression. Furthermore, Wiener et $a l^{16}$ have shown that the reproducibility of $\mathrm{pH}$ monitoring in determining abnormal levels of acid reflux is low in patients with borderline oesophageal acid exposure. As the prime objective of $\mathrm{pH}$ monitoring is to help determine appropriate management, a more useful approach may be the controlled single subject trial of acid suppression demonstrated in this study. A number of previous studies have adopted this approach in patients with GORD and atypical chest pain, using shorter courses of omeprazole $^{1718}$ or a single high dose of $80 \mathrm{mg}$ omeprazole. ${ }^{19} 20 \mathrm{~A}$ further advantage of this approach is that patients who we necessarily excluded because they were asymptomatic 
during $\mathrm{pH}$ monitoring, and for whom an SI could not be calculated, would be objectively evaluated in terms of responsiveness to acid suppression. An even more rigorous approach, when making management decisions about an individual patient, is an " $n$ of 1 " trial in which multiple treatments are administered to the patient in a double blind, randomised, multiple cross-over sequence. ${ }^{21-23}$

One of our patients had previously failed to respond to omeprazole $20 \mathrm{mg}$ daily but responded dramatically to the trial dosage of 20 mg twice daily. In this case, despite low levels of acid reflux, the patient's low threshold sensitivity required a high degree of acid suppression for symptom relief. Therefore, if a controlled single subject trial is to be used in practice, adequate acid suppression is necessary for valid assessment. Follow up study of this group of patients indicates that the condition tends to be recurrent and persistent. ${ }^{24}$ The natural history is similar to patients with GORD with erosive changes and they are likely therefore to require continued or repeated acid suppression therapy.

It is notable that symptoms of heartburn and acid regurgitation responded to acid suppression whereas the frequently present "associated symptoms" did not. Shi et al "11 also noted a high frequency of such symptoms in their patients with reflux symptoms and normal oesophageal acid exposure. They suggested that the symptoms of reflux seemed to overlap with the symptom pattern of functional dyspepsia. Trimble et $a l^{25}$ have shown that there is heightened non-site-specific visceral sensation, demonstrated by perception of balloon distension, in both the rectum and oesophagus, in patients with irritable bowel syndrome and functional dyspepsia. Therefore, if some "associated symptoms" are caused by dysmotility and distension from different parts of the gastrointestinal tract, it is not surprising that acid suppression has no effect. Although the numbers in the negative SI group are small the relative lack of responsiveness to acid suppression suggests that this group may be largely comprised of patients with a functional or motility disorder.

In conclusion, we contend that the "sensitive oesophagus" should be regarded as part of the spectrum of GORD. Although previously recognised in terms of $\mathrm{pH}$ monitoring, we suggest that it may be more appropriately defined by means of controlled assessment of responsiveness to acid suppression treatment. A recent study by Marrero et $a l^{26}$ in patients with GORD symptoms but without oesophagitis demonstrated that acid suppression treatment not only reduced acid reflux but also significantly raised threshold sensitivity in the oesophagus as determined by a timed acid perfusion test. Presumably, this change contributes to symptom relief. Further work is required to investigate the neuronal mechanisms which determine oesophageal sensitivity and its modulation. In future it may be possible to raise threshold sensitivity and produce symptom relief without prolonged unphysiological acid suppression.

This study did not receive any funding from the pharmaceutical industry.

1 Behar J, Biancani P, Sheahan DG. Evaluation of esophageal tests in the diagnosis of reflux esophagitis. Gastroenterology 1976; 71: $9-15$.

2 Johansson K-E, Ask P, Boeryd B, Fransson S-G, Tibbling L. Oesophagitis, signs of reflux and gastric secretion in patients with symptoms of gastro-oesophageal reflux disease. Scand $\mathcal{F}$ Gastroenterol 1986; 21: 837-47.

3 Knill-Jones RP, Card WI, Crean GP, James WB Spiegelhalter DJ. The symptoms of gastro-oesophagea reflux and of oesophagitis. Scand $\mathcal{F}$ Gastroenterol 1984; 19 (suppl 106): 72-6.

4 Little AG, De Meester TR, Kirchner PT, O'Sullivan GC, Skinner DB. Pathogenesis of oesophagitis in patients with gastroesophageal reflux. Surgery 1980; 88: 101-7.

5 McDougall NI, Dickey W, Johnston BT, Collins JSA, Love AHG. An audit of the role of ambulatory oesophageal $\mathrm{pH}$ monitoring in clinical practice. Eur $\mathcal{f}$ oesophageal $\mathrm{pH}$ monitoring in clinical

6 Johnston BT, McFarland RJ, Collins JSA, Love AHG. Are esophageal symptoms reflux related? A study of differen scoring systems in a cohort of patients with heartburn. $A m$ f Gastroenterol 1994; 89: 497-502.

7 Eriksen CA, Cullen PT, Sutton D, Kennedy N, Cuschieri A Abnormal esophageal transit in patients with typical reflux symptoms but normal endoscopic and $\mathrm{pH}$ profiles. $\mathrm{Am} \mathcal{F}$ Surg 1991; 161: 657-61.

8 Johnston BT, McFarland RJ, Collins JSA, Love AHG. The symptom index: a useful marker of gastro-oesophageal reflux disease. $B r$ F Surg 1992; 79: 1054-5.

9 Singh S, Richter JE, Bradley LA, Haile JM. The symptom index: differential usefulness in suspected acid-related complaints of heartburn and chest pain. Dig Dis Sci 1993; 38: 1402-8.

10 Trimble KC, Pryde A, Heading RC. Lowered oesophageal sensory thresholds in patients with symptomatic but not excess gastro-oesophageal reflux: evidence for a spectrum of visceral sensitivity in GORD. Gut 1995; 37: 7-12.

11 Shi G, Bruley Des Varannes S, Scarpignato C, Le Rhun M Galmiche J-P. Reflux related symptoms in patients with normal oeosphageal exposure to acid. Gut 1995; 37 457-64.

12 Jenkinson C, Coulter A, Wright L. Short form 36 (SF36) health survey questionnaire: normative data for adults of working age. BMF 1993; 306: 1437-40.

13 Brazier JE, Harper R, Jones NMB, O'Cathain A, Thomas KJ, Usherwood T, et al. Validating the SF-36 Thomas $\mathrm{KJ}$, Usherwood T, et al. Validating the SF-36 primary care. BMf 1992; 305: $160-4$.

14 Garratt AM, Ruta DA, Abdalla MI, Buckingham JK, Russell IT. The SF36 health survey questionnaire: an outcome measure suitable for routine use in the NHS $B M \Im$ 1993; 306: 1440-4.

15 McDougall NI, Johnston BT, Kee F, Collins ISA McFarland RJ, Watson RGP, Love AHG. The effect of healing of oesophagitis on patient quality of life. Gut 1994; 35 (suppl 5): S13.

16 Wiener GJ, Morgan TM, Copper PA, Wu WC, Castell DO, Sinclair JW, Richter JE. Ambulatory 24-hour esophageal pH monitoring: reproducibility and variability of $\mathrm{pH}$ pH monitoring: reproducibility and varia

17 Staun M, Rune SJ. Controlled single subject trial to identify patients with acid related dyspepsia. Scand $\mathcal{f}$ Gastroenterol 1992; 27 (suppl 190): 34 .

18 Richter JE, Schan C, Burgard S, Bradley L. Placebo controlled trial of omeprazole in the treatment of acidrelated non-cardiac chest pain (NCCP). Am $\mathcal{F}$ Gastroenterol 1992; 87: 1255

19 Young MF, Sanowski RA, Talbert GA, Harrison ME Walker BE. Omeprazole administration as a test for gastroesophageal reflux [abstract]. Gastroenterolgy 1992 102: A192.

20 Zierer ST, Sanowski RA, Young MF, Squillance SJ. Can a single dose of omeprazole be used to identify gastroesophageal reflux and acid-related chest pain? $A m \mathcal{F}$ Gastroenterol 1993; 88: 1501 .

21 Johannessen T, Fjøsne U, Kleveland PM, Halvorsen T, Kristensen P, Loge I, et al. Cimetidine responders in nonKristensen P, Loge I, et al. Cimetidine responders in non-
ulcer dyspepsia. Scand $₹$ Gastroenterol 1988; 23: 327-36.

22 Johannessen T. Controlled trials in single subjects. I. Value in clinical medicine. $B M F$ 1991; 303: 173-4

23 Lewis JA. Controlled trials in single subjects. II. Limitations of use. BMF 1991; 303: 175-6.

24 Trimble KC, Douglas S, Pryde A, Heading RC. Clinica characteristics and natural history of symptomatic but not excess gastroesophageal reflux. Dig Dis Sci 1995; 40 1098-104.

25 Trimble KC, Farouk R, Pryde A, Douglas S, Heading RC. Heightened visceral sensation in functional gastrointestinal disease is not site-specific. Evidence for a generalised disorder of gut sensitivity. Dig Dis Sci 1995 40: $1607-13$.

26 Marrero JM, de Caestecker JS, Maxwell JD. Effect of famotidine on oesophageal sensitivity in gastrooesophageal reflux disease. Gut 1994; 35: 447-50. 